Research Article

\title{
Three decades of studies on chromosomal polymorphism of Drosophila willistoni and description of fifty different rearrangements
}

\author{
Claudia Rohde* and Vera Lúcia S. Valente \\ Departamento de Genética, Instituto de Biociências, Universidade Federal do Rio Grande do Sul, \\ Porto Alegre, RS, Brazil.
}

\begin{abstract}
Drosophila willistoni (Insecta, Diptera) is considered a paradigm for evolutionary studies. Their chromosomes are characterized by multiple paracentric inversions that make it hard to identify and describe chromosomal polymorphisms. In the present report we attempted to systematize the description of all the 50 inversions found in the last three decades, since we have been studying the chromosomes of several individuals of 30 different populations, including the one used in the genome sequencing project $(G d-H 4-1)$. We present the photographic register of 11 arrangements in the left arm of the X chromosome (XL), eight in the right arm (XR), 10 in the left arm of chromosome II (IIL), eight in its right arm (IIR) and 13 in chromosome III. This information also includes their breakpoints on the reference photomap. A clear geographic difference was detected in $X L$ and $X R$, with different fixed arrangements depending on the origin of the population studied. Through the comparison of all $X$ arrangements it was possible to infer the putative ancestral arrangements, i.e., those related to all the remaining arrangements through the small number of inversions that occurred in the past, which we will call XL-A and XR-A. In the autosomes (IIL/IIR and III), fixed inversions were detected, but most are segregating in different frequencies along the geographical distribution of the D. willistoni populations.
\end{abstract}

Keywords: cytogenetic, polytene chromosomes, inversions, Drosophila willistoni.

\section{Introduction}

Sixty years after Dobzhansky (1950) first described the polytene chromosomes of Drosophila willistoni, the large number of chromosomal inversions found in populations of this species still attracts the attention of geneticists. When Dobzhansky first published his work, the focus was on evolution from a population genetics viewpoint (Dobzhansky and Powell, 1975; Ehrman and Powell, 1982; Krimbas and Powell, 1992). Now, D. willistoni is part of a bigger scenario of evolutionary studies on Drosophila that began with the publication of the comparative genome sequences of 12 closely related fruit fly species (Drosophila 12 Genomes Consortium, 2007). Ten species were sequenced for the first time $(D$. sechellia, $D$. simulans, $D$. yakuba, $D$. erecta, D. ananassae, D. persimilis, $D$. mojavensis, $D$. virilis, $D$. grimshawi and $D$. willistoni) and two were genomes of Drosophila melanogaster, which had

Send correspondence to Vera L.S. Valente. Departamento de Genética, Instituto de Biociências, Universidade Federal do Rio Grande do Sul, Av. Bento Gonçalves 9500, Caixa Postal 15053, 91501-970 Porto Alegre, RS, Brazil. E-mail: vera.gaiesky@ufrgs.br.

*Present address: Centro Acadêmico de Vitória, Universidade Federal de Pernambuco, Vitória de Santo Antão, Brazil. E-mail: claudiarohde@yahoo.com. previously been sequenced in 2000 (Adam et al., 2000), and D. pseudoobscura, published in 2005 (Richards et al., 2005). With these results, a rich source of genomic data is now available and can be used in comparisons to other important organisms, such as humans, as well as for identifying novel genes and other functional elements in insect genomes.

The results of the Drosophila 12 Genomes Consortium (2007) revealed that, despite the overall similarities, several unexpected differences occur among the species studied, especially in aspects related to ecology and behavior, reflecting adjustments to the vastly different environments in which they evolved. Among the sequenced species, Drosophila willistoni was the only Neotropical one, and proved to be exceptional in several aspects of its genome: its large genome size, unusually skewed codon usage, high content of transposable elements $(15 \%$, only lower than that of $D$. ananassae: $\sim 25 \%$ ) and an apparent lack of selenoproteins (Vicario et al., 2007).

This major genome sequencing and analysis effort has brought about the need to reevaluate the available physical maps, in part to aid the mapping of assembled scaffolds (Schaeffer et al., 2008). In Schaeffer et al. (2008) we presented a definitive and individual photomap of the polytene chromosomes of Drosophila willistoni used to anchor the 
assembled scaffolds of the Drosophila 12 Genomes Consortium (2007). The main results of this study are in agreement with Muller's idea that the chromosomes of different Drosophila species are syntenic with respect to their genic content, although several rearrangements occurred over time, including inversions and fusions (Muller, 1940). So, as a rule, even when an extreme rearrangement of the chromosome elements has occurred, synteny relationships usually remain relatively conserved (Bhutkar et al., 2008).

Drosophila willistoni has a wide distribution, extending from Mexico and Florida to southern Brazil, Argentina and Uruguay, and from the Atlantic to the Pacific Ocean (Spassky et al., 1971; Ehrman and Powell, 1982). It is the most common drosophilid species inhabiting South American forests. The chromosomes of natural populations of $D$. willistoni are characterized by multiple chromosome inversions (Sperlich and Pfriem, 1986; Krimbas and Powell, 1992; Powell, 1997) and in more than three decades working with this organism, we have never collected stable monomorphic populations in the field. This is the case for the southern borders of its geographical distribution, such as Uruguay, where the natural populations of $D$. willistoni still have a high level of polymorphism (Valente et al., 2001, 2003). This said, the vast chromosomal polymorphism for inversions is one of the paramount characteristics of this species (Burla et al., 1949; Da Cunha et al., 1950, 1959; Townsend, 1952; Da Cunha and Dobzhansky, 1954; Valente and Araújo, 1985, 1986; Valente et al., 1993; 2003; Rohde et al., 2005), and it appears that being chromosomally polymorphic is the rule for $D$. willistoni. Faced with this, it was a special challenge to choose one recent collected isofemale line of Drosophila willistoni to represent the species in the genome sequencing project (Drosophila 12 Genomes Consortium, 2007). GD-H4-1 was finally chosen for this purpose due to its lack of inversion heterozygosity. The strain is the result of various laboratory generations of single brother-sister mating descending from an isofemale line collected in the Caribbean island of Guadeloupe.

In common with several other species that belong to the Sophophora subgenus of Drosophila, D. willistoni has a high polymorphism for paracentric inversions. It is hard to explain why there are more inversions in the subgenus Sophophora than in Drosophila as a whole, but according to Sperlich and Pfriem (1986) this may be due to several factors, including genetics (more fragile chromosomes), ecology (these flies inhabit diversified environments) and history (phylogenetically old species may accumulate more inversions).

Literature reports are unclear regarding the real number of variants segregating in natural populations of $D$. willistoni. The criteria available for descriptions of polytene chromosome inversions are somewhat confusing, not only due to the more fragile structural nature of the chromosomes, but also due to imprecise descriptions of inversion breakpoints. The camera lucida drawings made by Dobzhansky (1950), Da Cunha and Dobzhansky (1954) and Da Cunha et al. $(1950,1959)$ show large numbers of inversions present in the same chromosome, making the identification of each particular inversion and respective breakpoints very difficult. This difficulty in accurately identifying inversions is also a consequence of the small size of several $D$. willistoni inversions, which hinders the recognition of several of these in homozygosis. Furthermore, the chromosomes of $D$. willistoni also present several ectopic pairings that make accurate analyses difficult. As a consequence, the estimates available for this high polymorphism in the literature consider only the arrangements in heterozygosis (Burla et al., 1949; Da Cunha et al., 1950; Townsend, 1952; Da Cunha and Dobzhansky, 1954; Dobzhansky, 1957; Valente and Araújo, 1985; 1986; Valente et al., 1993; 2003), resulting in an underestimation of the true number of variants segregating in the natural populations of $D$. willistoni.

Over the last three decades our group has worked towards producing a good photomap of $D$. willistoni polytene chromosomes. At first, Valente and Morales (1985) redrew the reference map of Dobzhansky (1950), improving the identification of landmark bands that are useful to understand complex inversion configurations. Subsequently, Regner et al. (1996) presented the first photomap of $D$. willistoni polytene chromosomes, considering the arrangements present in natural populations of southern Brazil as a base to map insertion sites of the $P$ transposable element. The value of this photomap, however, has proven to be restricted to populations inhabiting the southern reaches of the American continent. Further observations by Rohde (2000, Ph.D. dissertation, Federal University of Rio Grande do Sul, Porto Alegre), taking into consideration 22 American populations from Florida to Uruguay, concluded that different "standard" arrangements of the X chromosome occur along the geographical distribution of the species.

Herein we revised all these descriptions of inversions found in the salivary gland chromosomes, presenting new results in an attempt to systematize the knowledge of the $D$. willistoni chromosomal polymorphism based on $30 \mathrm{Neo-}$ tropical populations. This approach led to the detection of 50 different arrangements in all five chromosomal arms and the description of different geographical patterns of chromosome evolution in autosomes and the sex chromosome (X).

\section{Materials and Methods}

We studied 30 Drosophila willistoni populations collected at different times and from several areas (Table 1) of the Neotropical distribution range of this species (Spassky et al., 1971). The flies, maintained in the laboratory by mass crosses or as isofemale lines, were reared on corn flour culture medium (Marques et al., 1966) and kept at 
Table 1 - Description of 30 different Drosophila willistoni populations studied for chromosomal polymorphism.

\begin{tabular}{|c|c|c|c|}
\hline Population code & Place of collection & Latitude/Longitude & Collection Year (Collector) \\
\hline FLO & Florida, United States of America & $25^{\circ} 00^{\prime} \mathrm{N} / 81^{\circ} 20^{\prime} \mathrm{W}$ & Stock Center (-) \\
\hline MEX & Apazapan, Veracruz, Mexico & $19^{\circ} 15^{\prime} \mathrm{N} / 96^{\circ} 45^{\prime} \mathrm{W}$ & $1998(1)$ \\
\hline MON & Monkey Hill, Saint Kitts Island, Caribbean Sea & $17^{\circ} 19^{\prime} \mathrm{N} / 62^{\circ} 43^{\prime} \mathrm{W}$ & Stock Center (2) \\
\hline GUA & Guadeloupe Island, Caribbean Sea & $16^{\circ} 15^{\prime} \mathrm{N} / 61^{\circ} 35^{\prime} \mathrm{W}$ & Stock Center (3) \\
\hline ECU & Jatun Sacha, Tena, Napo, Ecuador & $01^{\circ} 06^{\prime} \mathrm{S} / 77^{\circ} 61^{\prime} \mathrm{W}$ & $1998(4)$ \\
\hline TRA & Santa Maria de Tracuateua, Moju, Pará, Brazil & $01^{\circ} 04^{\prime} \mathrm{S} / 46^{\circ} 53^{\prime} \mathrm{W}$ & $1990(5)$ \\
\hline PAR & Caxiuanã National Forest, Melgaço, Para, Brazil & $01^{\circ} 42^{\prime} \mathrm{S} / 51^{\circ} 31^{\prime} \mathrm{W}$ & $1997(5)$ \\
\hline MAN & Manaus, Amazonas, Brazil & $03^{\circ} 00^{\prime} \mathrm{S} / 60^{\circ} 00^{\prime} \mathrm{W}$ & $1986(5)$ \\
\hline $\mathrm{ZOO}$ & Zoo, Dois Irmãos Estadual Park, Recife, Brazil & $08^{\circ} 00^{\prime} \mathrm{S} / 34^{\circ} 56^{\prime} \mathrm{W}$ & $2008(6)$ \\
\hline CAT & Catimbau National Park, Buíque, Pernambuco, Brazil & $08^{\circ} 24^{\prime} \mathrm{S} / 37^{\circ} 09^{\prime} \mathrm{W}$ & $2008(6)$ \\
\hline WIP & Ipitanga, Lauro de Freitas, Bahia, Brazil & $12^{\circ} 54^{\prime} \mathrm{S} / 38^{\circ} 19^{\prime} \mathrm{W}$ & 1965 (7) \\
\hline BRA & Brasília, Distrito Federal, Brazil & $15^{\circ} 47^{\prime} \mathrm{S} / 47^{\circ} 55^{\prime} \mathrm{W}$ & $1999(8)$ \\
\hline PNE & National Park of Emas, Goiás, Brazil & $18^{\circ} 60^{\prime} \mathrm{S} / 52^{\circ} 00^{\prime} \mathrm{W}$ & $1993(-)$ \\
\hline $\mathrm{CIP}_{1}$ & Cipó Hill, Santana do Riacho, Minas Gerais, Brazil & $19^{\circ} 20^{\prime} \mathrm{S} / 43^{\circ} 40^{\prime} \mathrm{W}$ & $1995(9)$ \\
\hline $\mathrm{CIP}_{2}$ & Cipó Hill, Santana do Riacho, Minas Gerais, Brazil & $19^{\circ} 20^{\prime} \mathrm{S} / 43^{\circ} 40^{\prime} \mathrm{W}$ & $1996(9)$ \\
\hline RIB & Ribeirão Preto, São Paulo, Brazil & $21^{\circ} 10^{\prime} \mathrm{S} / 47^{\circ} 50^{\prime} \mathrm{W}$ & $1995(10)$ \\
\hline MEL & Mel Island, Paraná, Brazil & $25^{\circ} 32^{\prime} \mathrm{S} / 48^{\circ} 18^{\prime} \mathrm{W}$ & $1994(6)$ \\
\hline $\mathrm{TAB}$ & Tabuleiro Hill, Santa Catarina, Brazil & $27^{\circ} 42^{\prime} \mathrm{S} / 48^{\circ} 34^{\prime} \mathrm{W}$ & $1997(11)$ \\
\hline RAT & Ratones Grande Island, Santa Catarina, Brazil & $27^{\circ} 29^{\prime} \mathrm{S} / 48^{\circ} 36^{\prime} \mathrm{W}$ & $1997(11)$ \\
\hline ISC & Santa Catarina Island, Santa Catarina, Brazil & $27^{\circ} 42^{\prime} \mathrm{S} / 48^{\circ} 30^{\prime} \mathrm{W}$ & $1997(11)$ \\
\hline TUR & Turvo Estadual Park, Rio Grande do Sul, Brazil & $27^{\circ} 20^{\prime} \mathrm{S} / 53^{\circ} 10^{\prime} \mathrm{W}$ & $1994(12)$ \\
\hline DLA & Dois Lajeados, Rio Grande do Sul, Brazil & $29^{\circ} 10^{\prime} \mathrm{S} / 51^{\circ} 54^{\prime} \mathrm{W}$ & $1995(6)$ \\
\hline POA & Porto Alegre (18J), Rio Grande do Sul, Brazil & $30^{\circ} 02^{\prime} \mathrm{S} / 51^{\circ} 14^{\prime} \mathrm{W}$ & $1989(13)$ \\
\hline MSA & Santana Hill, Porto Alegre, Rio Grande do Sul, Brazil & $30^{\circ} 04^{\prime} \mathrm{S} / 51^{\circ} 08^{\prime} \mathrm{W}$ & $1995(12)$ \\
\hline $\mathrm{ITA}_{1}$ & Itapuã Estadual Park, Viamão, Rio Grande do Sul, Brazil & $30^{\circ} 17^{\prime} \mathrm{S} / 51^{\circ} 01^{\prime} \mathrm{W}$ & $1995(14)$ \\
\hline $\mathrm{ITA}_{2}$ & Itapuã Estadual Park, Viamão, Rio Grande do Sul, Brazil & $30^{\circ} 17^{\prime} \mathrm{S} / 51^{\circ} 01^{\prime} \mathrm{W}$ & $1997(14)$ \\
\hline COR & La Coronilla, Rocha, Uruguay & $33^{\circ} 56^{\prime} \mathrm{S} / 53^{\circ} 85^{\prime} \mathrm{W}$ & $1994(15)$ \\
\hline TER & Santa Teresa National Park, Castillos, Rocha, Uruguay & $33^{\circ} 58^{\prime} \mathrm{S} / 53^{\circ} 32^{\prime} \mathrm{W}$ & $2003(6)$ \\
\hline MVD & Montevideo, Montevideo, Uruguay & $34^{\circ} 83^{\prime} \mathrm{S} / 56^{\circ} 16^{\prime} \mathrm{W}$ & $2000(15)$ \\
\hline PIR & Piriapolis, Maldonado, Uruguay & $34^{\circ} 86^{\prime} \mathrm{S} / 55^{\circ} 27^{\prime} \mathrm{W}$ & $1994(15)$ \\
\hline
\end{tabular}

Numbers in the last column refers to the name of flies' collectors: (1) Joana Carneiro da Silva, (2) David Bruck, (3) Peter Chabora, Lee Ehrman and Jeffrey R. Powell, (4) Patrick O’Grady, (5) Marlúcia Martins, (6) Claudia Rohde, (7) Antônio Rodrigues Cordeiro and Helga Winge, (8) Rosana Tidon, (9) Carlos R. Vilela and L. Mori, (10) Fabio de Melo Sene, (11) Daniela Cristina De Toni and Paulo Roberto Petersen Hofmann, (12) Luciano Basso da Silva, (13) Luciana Pereira Regner, (14) Luciano Basso da Silva and Victor Hugo Valiati, (15) Beatriz Goñi.

$17 \pm 1{ }^{\circ} \mathrm{C}$ and $60 \%$ relative humidity. Three populations (FLO, WIP and PNE) were old stocks from UFRGS Department of Genetics. Besides FLO, two others (MON and GUA) were also obtained from the Stock Center at Tucson/Arizona and represent inbred lines originally collected from Central America islands. All five stocks had been maintained for many years in the laboratory and thus a substantial reduction in genetic variability was to be expected. The other 25 populations were recently collected by us or kindly sent in by collaborators (Table 1). They represent isofemale lines of at least 10 inseminated females per population.

Squash mounts of polytene chromosomes present in salivary gland cells of third instar larvae were made using a modification of the technique described by Ashburner (1967), fixed with acetic acid (45\%), transferred to a drop of acetic acid, lactic acid and water $(3: 2: 1)$ and stained with acetic orcein $(2 \%)$. For each larvae, inversion polymorphism characterization was made by photomicrographic analysis of the five long chromosomal arms (XL, XR, IIL, IIR and III) of the chromosome set using a Zeiss photomicroscope and phase contrast at $1000 \mathrm{X}$ magnification. The photomicrographs were edited using Adobe Photoshop 5.0 and CorelDraw X3. The usual procedure adopted to study chromosomal inversions in Drosophila (analysis of the chromosomes of larvae produced by crossing males of unknown karyotype with homokaryotypic females of 
known karyotype) was not employed due to the virtual absence of homokaryotypic viable stocks of $D$. willistoni.

Chromosomal polymorphism of $D$. willistoni was studied according to the reference photomap published in Schaeffer et al. (2008) for each chromosomal arm. This photomap is being presented here in only one standard picture, with all chromosomal arms together (Supplementary Material, Figure S1). Both heterozygous and homozygous inversions were analyzed and counted for frequency analysis. For the calculation of inversion frequencies we considered each inversion in the heterozygous state once, and each inversion in the homozygous state (representing each chromosome homologue) twice. The total number of chromosomal arms analyzed was twice the number of individuals analyzed.

The similarity index was calculated based on the number and frequency of paracentric inversions among 30 geographical populations. The resulting dendrogram was generated with Past version 2.04 (Hammer et al., 2001) and the Morisita index (Morisita, 1959).

\section{Results}

Figures 1 to 5 present the configuration of different arrangements of XL, XR, IIL, IIR and III chromosome of D. willistoni, with their own inversions. Table 2 presents the frequency of 50 different arrangements found in 30 populations studied. Inversions IIL-D and IIL-E are difficult to tell apart, and for this reason, are grouped for frequency analysis in Table 2.

All the photomaps and photomicrographs (Figures 1 to 5) are oriented the same way, with the proximal (centromeric) regions of the chromosomes to the left and the distal (free) regions to the right. The distal regions of the chromosomes are usually well polytenized and allow the different chromosomes to be recognized. Since there are different fixed configurations for the XL and XR chromosomal arms, we use capital letters to distinguish between them, like XL-A or XR-A, both presented in the standard photomap of the species (Figure S1). In total, we observed at least 10 different chromosomal arrangements segregating on the $\mathrm{XL}$ arm and eight on the XR arm. Two XL arrangements, $\mathrm{XL}-\mathrm{C}$ and $\mathrm{XL}-\mathrm{H}$, were found only in the homozygous state (data not shown) and two inversions (XL-J and XL-I, Figure 1) were only found by Regner and Valente (unpublished data) for other Southern Brazilian populations. Rohde et al. (2005) reported the unique pericentric inversion found until now in D. willistoni (XL/XR-p), both in homo and heterozygous states. In the autosomes, we were able to detect 10 different arrangements on the IIL arm, eight on the IIR arm and 13 on the III chromosome. As shown in Figures 1 to 5, the precise identification of each breakpoint of the 50 different arrangements was possible, or facilitated, because many inversions were detected in the homozygous state. Although heterozygous inversions are easily detected in cytological preparations the breakpoints are very often concealed above the loop, especially in very small inversions that are common in $D$. willistoni. This is probably one of the reasons why there has been, until now, a virtual absence in the literature of descriptions of homozygous inversions in $D$. willistoni.

Figures 1 and 2 also present an estimated evolutionary relationship between the arrangements of $\mathrm{XL}$ and those of XR. For example, the inversions (In) $\left(\mathrm{XL} \mathrm{F}_{1}+\mathrm{F}_{2}\right.$ occurred over the fixed inversion $(\mathrm{XL}) \mathrm{D}$, which in turn occurred over the XL-A standard. One possible evolutionary relationship (that will be presented in detail in another paper, with descriptions and comparisons of their homozygous forms) is that different arrangements of XL and also of XR can have occurred and were selected along the wide geographic distribution of $D$. willistoni. We propose that $\mathrm{XL}-\mathrm{A}$ is the ancestral configuration, and XL-D, XL-E and $\mathrm{XL}-\mathrm{B}$ are descendant forms with their own inversions, respectively: $\operatorname{In}(\mathrm{XL}) \mathrm{F}_{1}+\mathrm{F}_{2}, \operatorname{In}(\mathrm{XL}) \mathrm{B}, \mathrm{G}$, and $\operatorname{In}(\mathrm{XL}) \mathrm{J}, \mathrm{K}, \mathrm{I}$. As shown in Table 2, the inversion frequency of all arrangements of XL, and also XR segregate in different frequencies with a clear latitudinal cline, from North to South America. Compared to the XR chromosomal arm, the XL one presents a more fixed arrangement (4 to 3 ) among populations. On the other hand, all the autosomes (IIL, IIR and III) have a basic arrangement, within which may occur different inversions, but with a clear latitudinal cline of the respect frequencies, similar to what was seen for the $\mathrm{X}$ chromosome. By combining all inversion frequencies, a dendrogram was generated (Figure 6) showing that geographically proximate populations are much more closely related.

\section{Discussion}

In the present study, we tried to catalog the chromosomal inversions occurring in 30 Drosophila willistoni populations representative of almost its entire geographical distribution and to draw a general picture of the chromosomal inversion polymorphisms for this organism. We were able to analyze the chromosomes of $615 \mathrm{D}$. willistoni individuals, most of them being isofemale lines from natural populations. We found at least 50 different gene arrangements for various parts of the distribution range of the species, with evidence suggesting that northern and southern groups emerged gradually. With respect to the chromosomal arms XL and XL, our data are comparable with those reported by Levitan (1992), reviewing data of D. robusta and including his findings and those of Carson and Stalker (1947). The existence of inversion clines, with a tendency to lose heterokaryotypes toward the periphery of the species distribution (Carson, 1959) was partially found in Drosophila willistoni, especially with respect to the autosomes (Valente et al., 2003). Our data on D. willistoni inversions from Uruguayan populations, however, are not indicative of less polymorphism in the marginal populations in the extreme south of the distribution of this species 

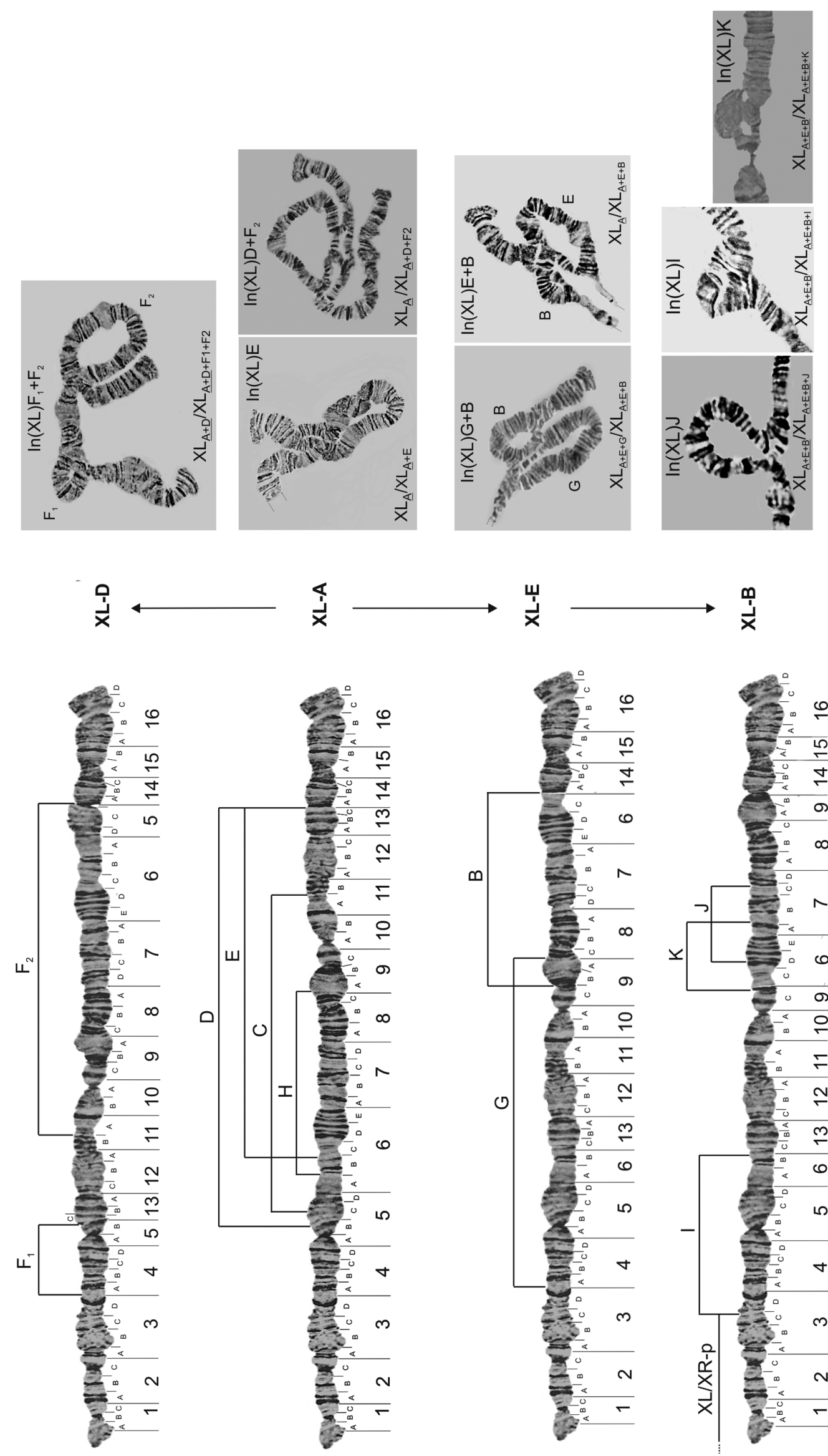

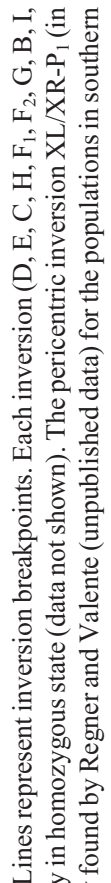

$\therefore \frac{1}{\square}$

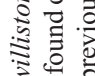

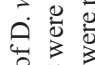

กิ

文必

है

된

死主

ดิ

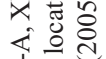

弎.

호웜

플 00

䜦苛

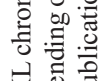

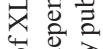

苛高

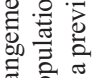

를 ․․․

.

氜

预

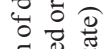

总遂 00

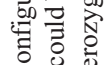

工

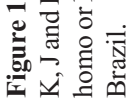



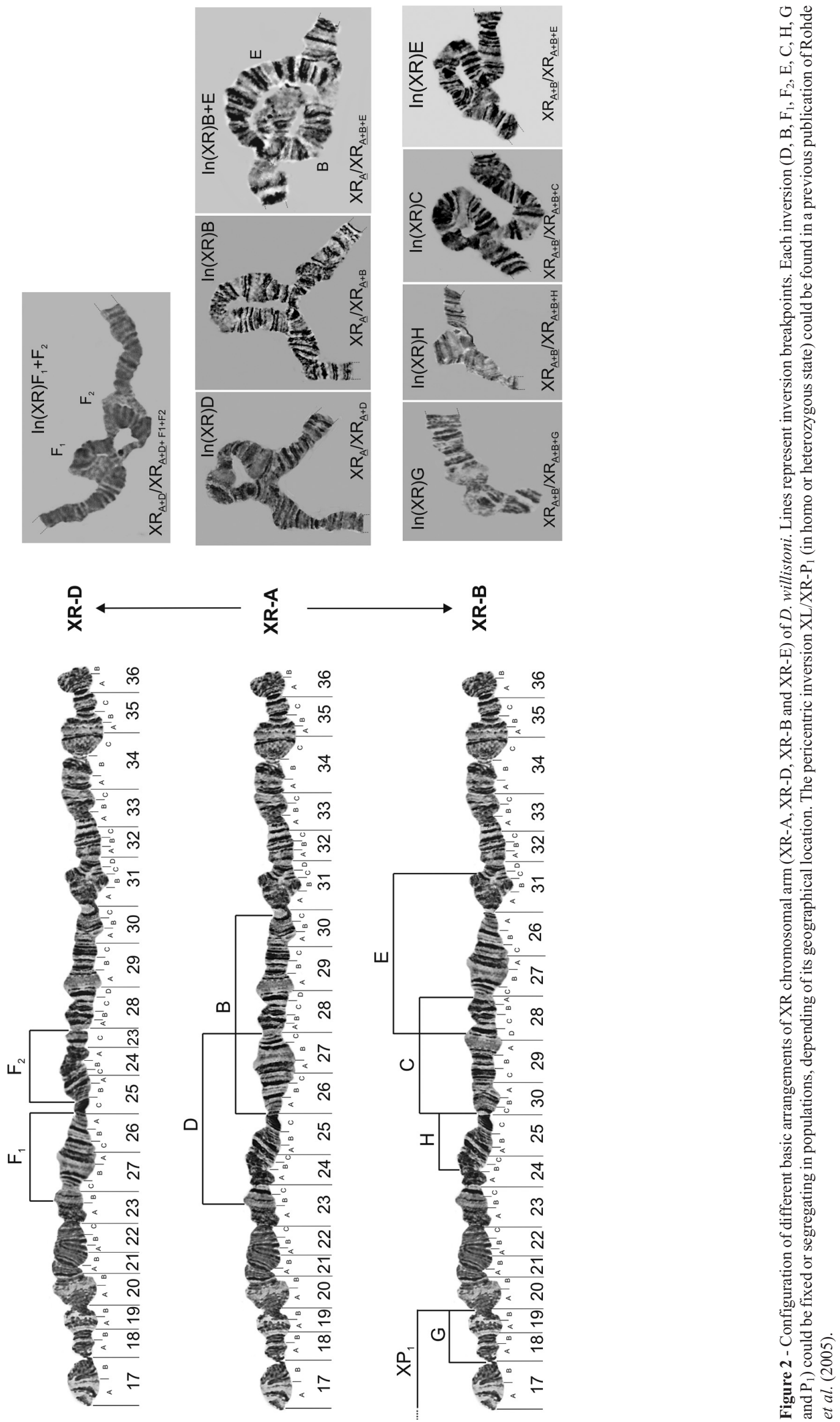


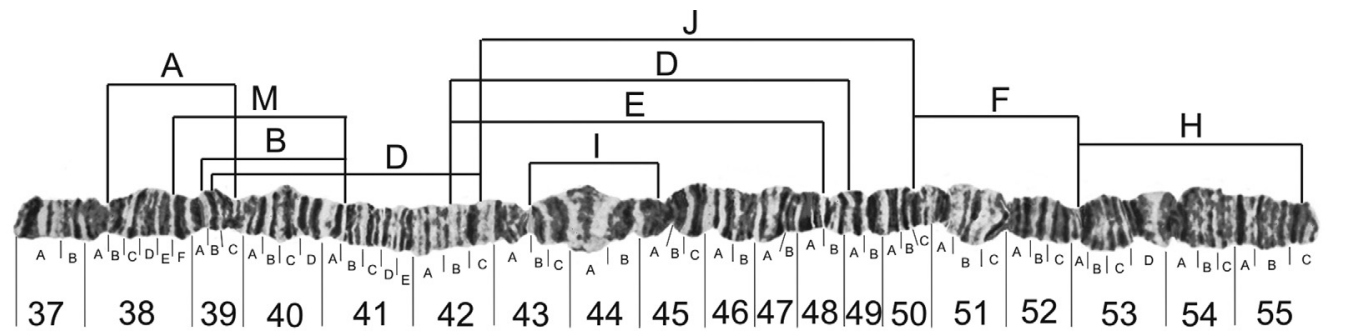

IIL

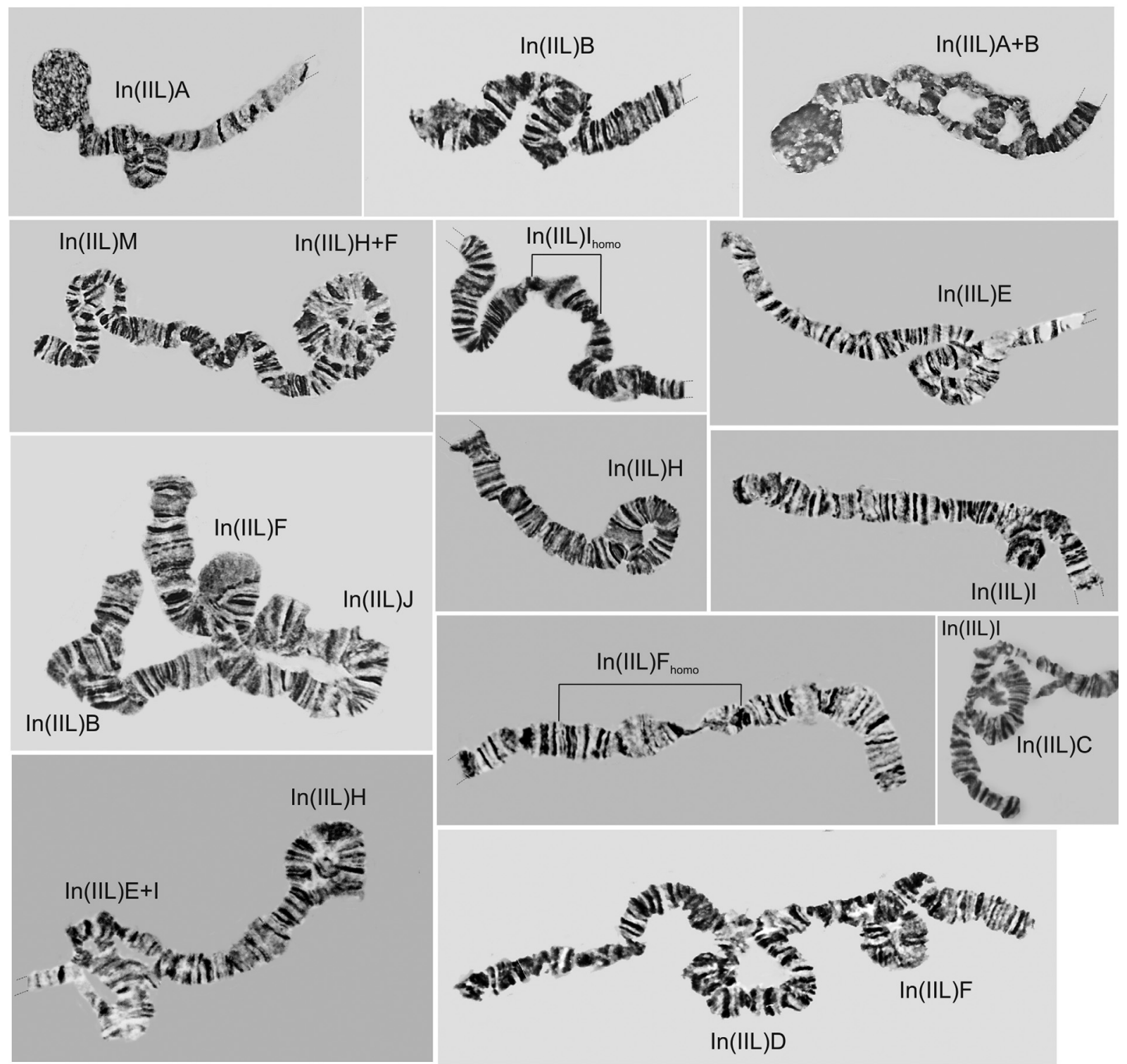

Figure 3 - Distribution of inversion breakpoints observed on chromosomal arm IIL of D. willistoni and photomicrographs of inversions (in homo and heterozygous state) detected.

(Valente et al., 2003). Chromosomal variation found in $D$. willistoni was mainly due to inversions and, for the first time, homozygous inversions were identified and included in the chromosomal polymorphism analysis. This was due to careful maintenance of isofemale lines, which allowed us to obtain chromosomal preparations of high resolution quality. The precise analysis of each inversion was done through the use of several different photomicrographs representing all possible configurations. This was also done for homozygous chromosomal arms.

Due to the large number of inversions and different types of combination of arrangements, a definitive discus- 

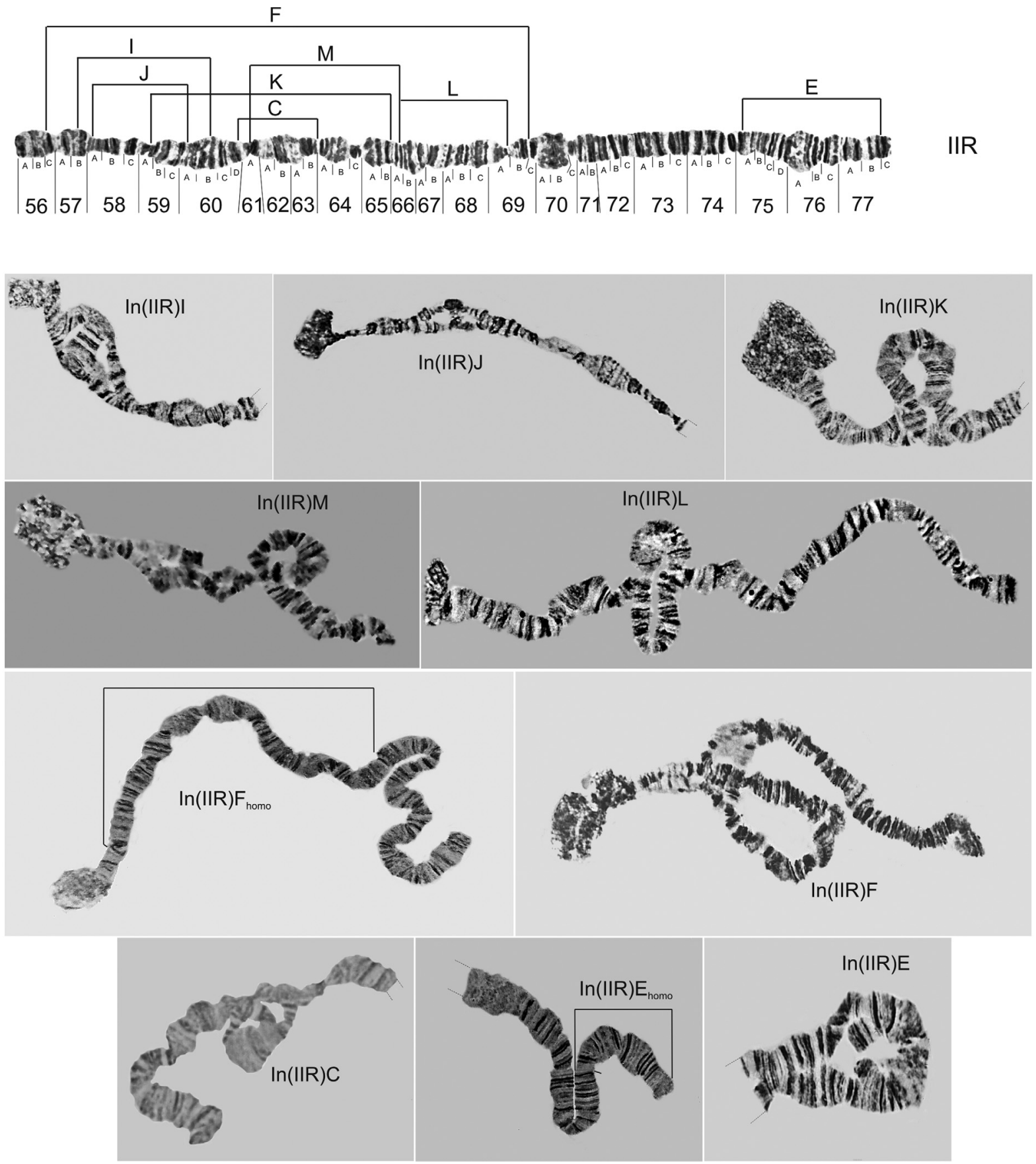

Figure 4 - Distribution of inversion breakpoints observed on chromosomal arm IIR of D. willistoni and photomicrographs of inversions (in homo and heterozygous state) detected.

sion on their macro-geographic distribution will be dealt with in upcoming paper. Nonetheless, some generalizations can be made. None of the sampled natural population was totally chromosomally monomorphic for all chromosomal arms. With respect to the $\mathrm{X}$ chromosome, a clear discontinuity of arrangements among populations was observed (Table 2). The 18 central-south Brazilian and Uruguayan populations (BRA to PIR) mainly presented the XL-B or XL-E, and XR-B or XR-E arrangements. Three northern Brazilian populations (ZOO, CAT and WIP) presented both standard arrangements as fixed: XL-A and XR-A. The other north Brazilian populations (MAN, TRA, PAR) and ECU, MEX and FLO mainly presented the XL-D or $\mathrm{XL}-\mathrm{F}_{1}+\mathrm{F}_{2}$, and $\mathrm{XR}-\mathrm{F}$ or XR-D. Finally, two Caribbean island populations (MON and GUA) presented the arrangements XL-A and XR-C as fixed. The XL-A arrangement, considered as the standard arrangement in D. willistoni (Schaeffer et al., 2008), was found in samples as far away as MEX (close to the north limit of the species range) and ITA (close to south limit of the species range), with fre- 

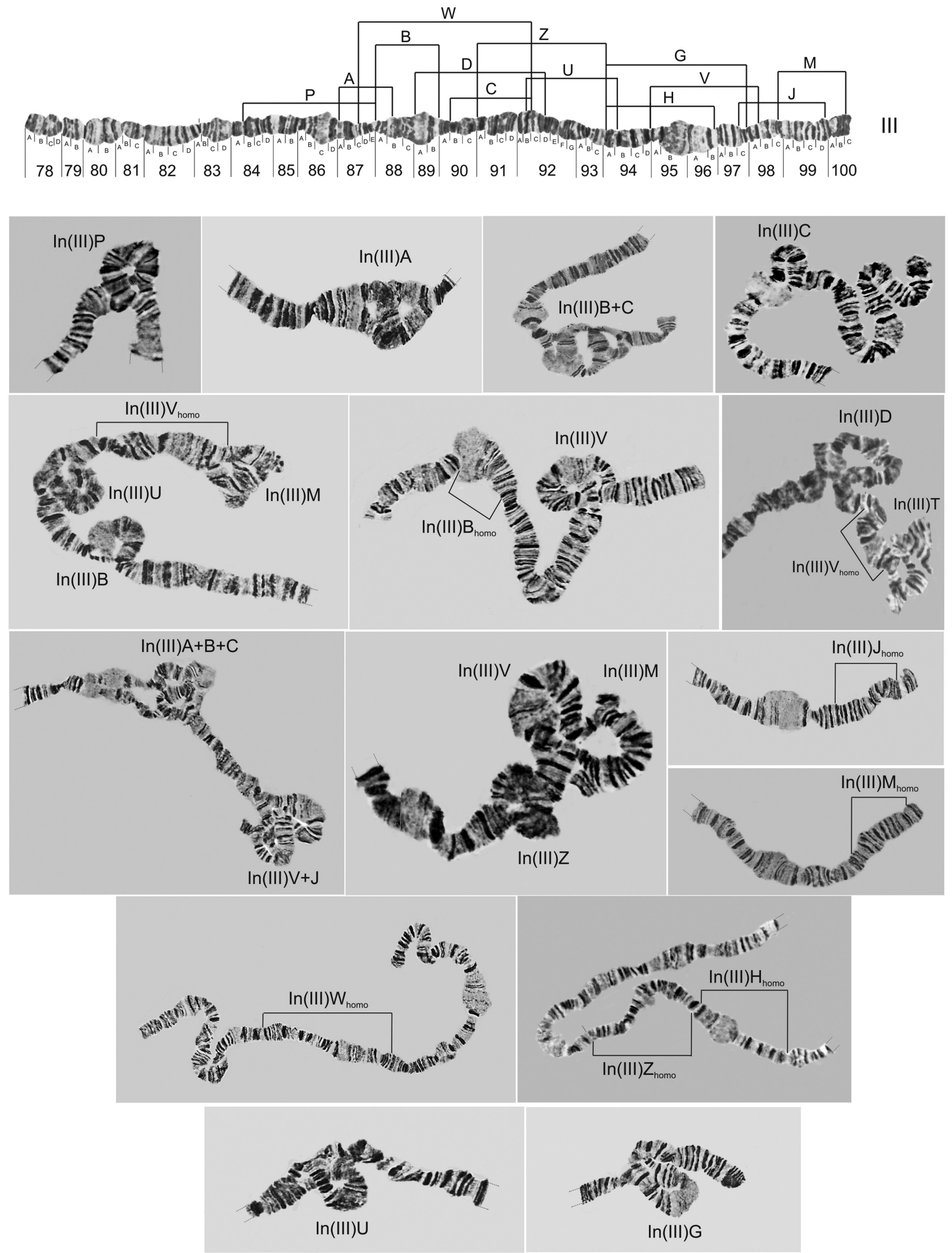

Figure 5 - Distribution of inversion breakpoints observed on chromosome III of D. willistoni and photomicrographs of inversions (in homo and heterozygous state) detected. 


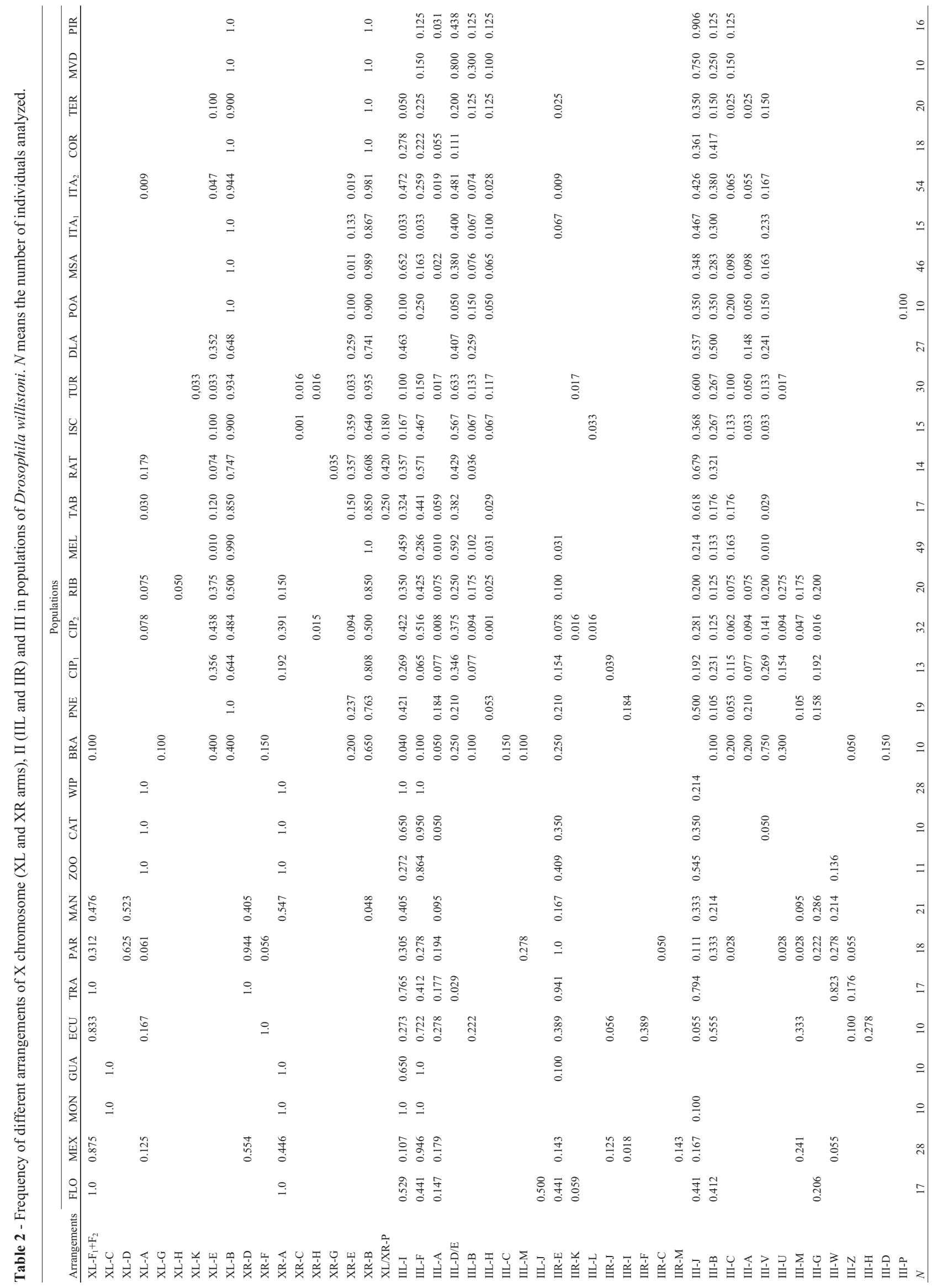


quencies varying between 0.009 and 0.179 , being exclusive to northern populations of Brazil (Table 2). With respect to XR-A, found in samples from FLO (in the north limit of the species range) to RIB (central Brazil) their frequencies ranged from 0.150 to 0.548 , being fixed in six different populations, as presented in Table 2 .

It is interesting to note in Table 2 that in each population analyzed just one or two possible arrangement of the XL or XR chromosomal arms were observed at frequencies above 0.1 (or 10\%). Wallace (1953 a, b) hypothesized that the simultaneous presence in a population of three successively overlapping inversions creates difficulties in maintaining a co-adaptive system (i.e., co-adaptation for the three possible pairs of inversions), since crossovers create a linkage of alleles between the two remote members of the triad. Because of this, a co-adaptive system would not be maintained. Our data regarding the arrangements of the X chromosome found that the populations of D. willistoni studied (except population BRA) are in accordance with Wallace's predictions, but Krimbas and Loukas (1980) found that there were 46 exceptions $(11.7 \%)$ to Wallace's rule among of a total of 394 cases of polymorphism in one of the chromosomes of a $D$. subobscura population. The authors suggested that in a chromosome triad, a frequency of 0.0005 (or $0.05 \%$ ) was the minimum possible for any of the three coexisting members. If we accept that this is also true for the X-chromosomes of our $D$. willistoni populations, then some populations for the XL arm (PAR, CIP 2 , BRA, RIB, TAB, RAT, TUR and $\mathrm{ITA}_{2}$ ) and some for the XR arm (MAN, BRA, CIP 2 , RAT, ISC and TUR) would also be exceptions to Wallace's rule. Table 2 shows that not just three, but four arrangements exist (in populations BRA, RIB and TUR), produced by successive overlapping inversions, if the frequency limit of the less frequent inversion is raised to 0.001 (or $0.10 \%$ ).

In the autosomes of $D$. willistoni, we observed regional characteristics regarding inversion frequencies, with some arrangements appearing to be fixed in some populations (IIL-I and IIL-F in the WIP population and IIR-E in the PAR population, for example) while other arrangements occurred at very high frequencies (IIL-I in the TRA population, IIL-F in MEX and ECU populations, IIR-E in the TRA population, III-W in the TRA population and III-J in TRA and PIR populations). However, it is possible that at least the inversions referred to by Da Cunha et al. (1950) as the most common ones (IIL-F, IIR-E, III-J, III-B) are the same inversions described here. In Figure 5, one can see that chromosome III, the most polymorphic among the autosomes, has many inversions that are separated from each other by only a few sections. So it is possible that we may have made mistakes when trying to correlate photomicrographs of this chromosome with the drawings made by previous authors, although we tried to minimize such errors by naming the inversions as they were found and compar- ing them with the map of Valente and Morales (1985), preserving the original descriptions.

From the dendrogram presented in Figure 6, the conclusion is that the analysis of heterozygous and homozygous frequency inversions in $D$. willistoni chromosomes is a good method for grouping populations. It can be also seen that geographically isolated populations, such as ECU and BRA, form two unique clusters, with the BRA population equally distant from the two biggest clusters, the southern and northern ones. Our results also support the theory that $\mathrm{X}$ chromosomes and autosomes are under different selective pressures and shed light on the particular chromosomal phylogeny of the $\mathrm{X}$ chromosome of $D$. willistoni, which will be published in more detail elsewhere. Due to the presence of fixed rearrangements in the $\mathrm{X}$ and other chromosomes, we do not recommend that only heterozygous inversions be used in inversion polymorphism analyses of this species.

Unfortunately, it was very difficult to compare our results with other previous publications, since few of them included photomicrographs of the inversions in the heterozygous state or their breakpoints in a photomap. This is the case with two recent interesting chromosomal studies on $D$. willistoni populations from Mexico (Salceda, 2006, 2010). The author found two frequent arrangements segregating in the XL chromosomal arm (XL "A" and "D") plus the standard "ST", and two arrangements in XR (XL "D" and "E") plus the standard "ST". Considering the frequencies of XL and XR presented by the author, it could be suggested that $\mathrm{XL}$ "ST" is our XL-F, being an arrangement resulting from two homozygous inversions occurring at the same time, $\mathrm{In}(\mathrm{XL}) \mathrm{F}_{1}+\mathrm{F}_{2}$ (as presented in Figure 1). When both inversions $\left(\mathrm{F}_{1}\right.$ and $\left.\mathrm{F}_{2}\right)$ occur together in both chromosomal arms $\mathrm{XL}$ of the same female (so, in homozygosis) they originate the arrangement XL-F, present in our Mexican populations at a frequency of 0.875 (or $87.5 \%$ ) (data not shown). With respect to XR "ST", it's not possible to suggest correlations with our data because we found two XR homozygous arrangements at similar frequencies: XL-A (0.357) and XL-D (0.464). Besides XL "ST", Salceda (2010) found seven more XL inversions, and besides XR "ST", six more inversions in XR.

Due to the presence of paracentric inversions, the rate of genome rearrangement in Drosophila is one of the highest among all eukaryotes (Ranz et al., 2001; González et al., 2007; Bhutkar et al., 2008). Ranz et al. (2001) estimated that between the Drosophila and Sophophora subgenera, for example, the evolution rate was 0.9-1.4 chromosomal inversions fixed per million years, based on the divergence time between the subgenus (Spicer, 1988; Russo et al., 1995). According to Richard et al. (2005), selection may favor inversions because they maintain epistatic combinations within the inverted segment (Dobzhansky 1949; Charlesworth and Charlesworth 1973; Wu and Beckenbach, 1983; Otto and Barton, 2001), 

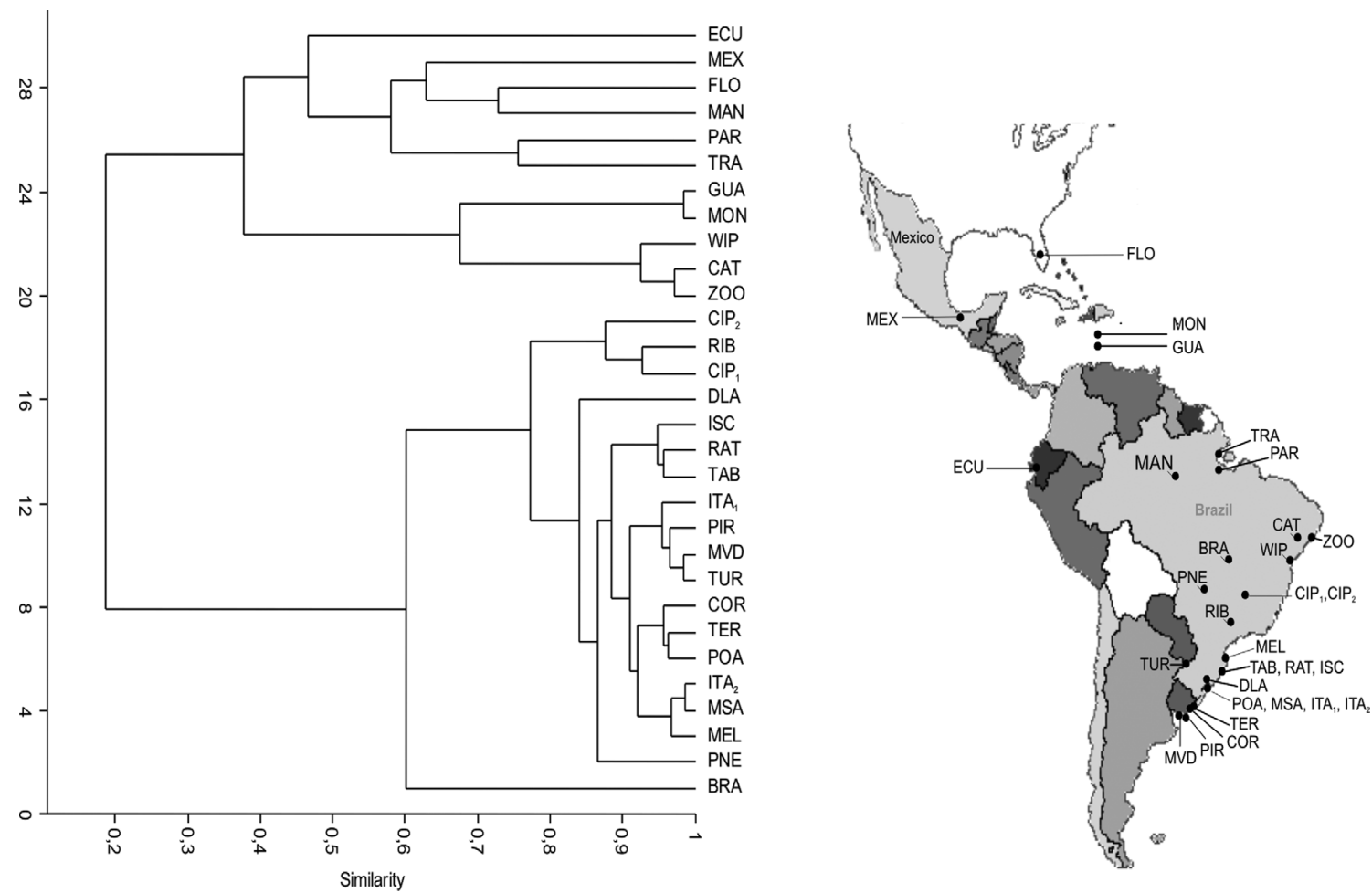

Figure 6 - Chromosomal arrangements of $D$. willistoni and their geographic distribution in the Americas. On the left, dendrogram similarity (Morisita index) based on the frequency of different paracentric arrangements found in all polytene chromosomes of the D. willistoni populations studied, On the right, map of the Americas showing the geographic locations where populations were sampled.

or selection may favor rearrangements that reorganize genes into clusters of coordinately expressed genes (Roy et al., 2002; Spellman and Rubin, 2002; Lercher et al., 2003). Once established in populations, chromosomal inversions may play a role in the formation of new species (Noor et al., 2001; Navarro and Barton, 2003). These aspects made it possible to use the recognition of inversion to reconstruct phylogenies between closely related species, as done by Rohde et al. (2006) for the willistoni subgroup.

For all these results to be interpreted correctly, one source of error must be accounted for, that is the low resolution of the cytological analysis of populations or species studied. For example, if two subsequent inversions with similar or identical breakpoints are overlooked, then they will produce a chromosome arrangement very similar to the ancestral one and a phylogenetic link could be missed (Ruiz et al., 1990; Ruiz and Wasserman 1993; Diniz and Sene 2004). Conversely, two different inversions may be mistakenly identified as the same inversion, creating a false phylogenetic link between two unrelated species. All these observations mean that chromosomal polymorphism deserves further studies that could include the detailed description of inversions, like photomicrographs and breakpoint descriptions over a unique photomap, allowing findings to be compared with each other, thus adding to the knowledge about the chromosomal polymorphism of $D$. willistoni and all related Neotropical species.

\section{Acknowledgments}

This work was supported by the Conselho Nacional de Desenvolvimento Científico e Tecnológico (CNPq to CR and VLSV), Fundação de Amparo à Ciência e Tecnologia do Estado de Pernambuco (FACEPE to CR) and PRONEX-FAPERGS (10/0028-7). The authors are very grateful to Drs. Ana Cristina Lauer Garcia, Luciano Basso da Silva and Marialva Sinigaglia for the help and constructive comments, and many other collaborators for kindly providing some of the strains.

\section{References}

Adam MD, Celniker SE, Holt RA, Evans CA, Gocayne JD, Amanatides PG, Scherer SE, Li PW, Hoskins RA, Galle RF, et al. (2000) The genome sequence of Drosophila melanogaster. Science 287:2185-2195.

Ashburner M (1967) Patterns of puffing activity in the salivary gland chromosomes of Drosophila. I. Autosomal puffing patterns in a laboratory stock of Drosophila melanogaster. Chromosoma 27:47-63.

Bhutkar A, Schaeffer SW, Russo S, Xu M, Smith TF and Gelbart WM (2008) Chromosomal rearrangement inferred from comparisons of 12 Drosophila genomes. Genetics 179:1657-1680.

Burla H, Da Cunha AB, Cordeiro AR, Dobzhansky T, Malagolowkin C and Pavan C (1949) The willistoni group of sibling species of Drosophila. Evolution 3:300-314. 
Carson HL and Stalker HD (1947) Gene arrangements in natural populations of Drosophila robusta Sturtevant. Evolution 1:113-133.

Carson HL (1959) Genetic conditions that promote or retard the formation of species. Cold Spring Harb Symp Quant Biol 24:87-105.

Charlesworth B and Charlesworth D (1973) Selection of new inversion in multi-locus genetic systems. Genet Res 21:167183.

Da Cunha AB and Dobzhansky T (1954) A further study of chromosomal polymorphism in Drosophila willistoni in its relation to the environment. Evolution 8:119-134.

Da Cunha AB, Burla H and Dobzhansky T (1950) Adaptive chromosomal polymorphism in Drosophila willistoni. Evolution 4:212-235.

Da Cunha AB, Dobzhansky T, Pavlovsky O and Spassky B (1959) Genetics of natural populations. XXVIII. Supplementary data on the chromosomal polymorphism in Drosophila willistoni in its relation with the environment. Evolution 13:389-404.

Dobzhansky T (1949) Observations and experiments on natural selection in Drosophila. Hereditas 35:210-224.

Dobzhansky T (1950) The chromosomes of Drosophila willistoni. J Hered 41:156-158.

Dobzhansky T (1957) Genetics of natural populations. XXVI. Chromosomal variability in island and continental populations of Drosophila willistoni from Central America and the West Indies. Evolution 11:280-293.

Dobzhansky T (1965) "Wild" and "Domestic" species of Drosophila. In: Backer HG and Stebbins GL (eds) The Genetics of Colonizing Species. Academic Press, New York, pp 533-546.

Dobzhansky T and Powell JR (1975) The willistoni group of Drosophila. In: King RC (ed) Handbook of Genetics. Plenum Press, New York, vol 3, pp 587-622.

Drosophila 12 Genomes Consortium (2007) Evolution of genes and genomes on the Drosophila phylogeny. Nature 450:203-218.

Ehrman L and Powell JR (1982) Drosophila willistoni species group. In: Ashburner M, Carson HL and Thompson Jr JN (eds) The Genetics and Biology of Drosophila. Academic Press, London, vol 3b, pp 193-225.

Levitan M (1992) Chromosomal variation in Drosophila robusta Sturtevant. In: Krimbas CB and Powell JR (eds) Drosophila Inversion Polymorphism. CRC Press, Boca Raton, pp 221-338.

Krimbas CB and Loukas M (1980) The inversion polymorphism of Drosophila subobscura. Evol Biol 12:163-234.

Krimbas CB and Powell JR (1992) Drosophila Inversion Polymorphism. CRC Press, Boca Raton, 560 pp.

Lercher MJ, Blumenthal T and Hurst LD (2003) Coexpression of neighboring genes in Caenorhabditis elegans is mostly due to operons and duplicate genes. Genome Res 13:238-243.

Marques EK, Napp M, Winge H and Cordeiro AB (1966) A cornmeal, soybean flour, wheat germ medium for Drosophila. Drosophila Inform Serv 41:187.

Morisita M (1959) Measuring of the dispersion and analysis of distribution patterns. Mem Fac Sci Kyushu Univ Ser E Biol 2:215-235.
Muller HJ (1940) Bearings of the Drosophila work on systematics. In: Huxley J (ed) The New Systematics. Clarendon Press, Oxford, pp 185-268.

Navarro A and Barton NH (2003) Accumulating postzygotic isolation genes in parapatry: A new twist on chromosomal speciation. Evol Int J Org Evol 57:447-459.

Noor MA, Grams KL, Bertucci LA and Reiland J (2001) Chromosomal inversions and the reproductive isolation of species. Proc Natl Acad Sci USA 98:12084-12088.

Otto SP and Barton NH (2001) Selection for recombination in small populations. Evol Int J Org Evol 55:1921-1931.

Powell JR (1997) Progress and Prospects in Evolutionary Biology: The Drosophila Model. Oxford University Press, Oxford, pp 562.

Ranz JM, Casals F and Ruiz A (2001) How malleable is the eukaryotic genome? Extreme rate of chromosomal rearrangement in the genus Drosophila. Genome Res 11:230239.

Regner LP, Pereira MSO, Alonso CEV, Abdelhay E and Valente VLS (1996) Genomic distribution of $P$ elements in Drosophila willistoni and a search for their relationship with chromosomal inversions. J Heredity 87:191-198.

Richards S, Liu Y, Bettencourt BR, Hradecky P, Letovsky S, Nielsen R, Thornton K, Hubisz MJ, Chen R, Meisel RP, et al (2005) Comparative genome sequencing of Drosophila pseudoobscura: Chromosomal, gene, and cis-element evolution. Genome Res 15:1-18.

Rohde C, Degrandi TH, De Toni, DC and Valente VLS (2005) Drosophila willistoni polytene chromosomes. I. Pericentric inversion on X chromosome. Caryologia 58:249-254.

Rohde C, Garcia ACL, Valiati VH and Valente VLS (2006) Chromosomal evolution of sibling species of the willistoni group of Drosophila. I. Chromosomal arm IIR (Muller's element B). Genetica 126:77-88.

Roy PJ, Stuart JM, Lund J and Kim SK (2002) Chromosomal clustering of muscle-expressed genes in Caenorhabditis elegans. Nature 418:975-979.

Salceda VM (2006) Chromosomal polymorphism in a natural population of Drosophila willistoni (Diptera, Drosophilidae) from Laguna Verde, Veracruz, Mexico: An eight-year record. Southw Nat 51:320-325.

Salceda VM (2010) A prospective study of inversion polymorphism in natural populations of two Drosophila species from Eastern Mexico. Genetika 42:407-414.

Schaeffer SW, Bhutkar A, Mcallister BF, Matsuda M, Matzkin LM, Rohde C, Valente VLS, Aguadé M, Anderson WW, Edwards K, et al. (2008) Polytene chromosomal maps of 11 Drosophila species: The order of genomic scaffolds inferred from genetic and physical maps. Genetics 179:1601-1655.

Spassky B, Richmond RC, Pérez-Salas S, Pavlovsky O, Mourão CA, Hunter AS, Hoenigsberg H, Dobzhansky T and Ayala FJ (1971) Geography of the sibling species related to Drosophila willistoni and the semispecies of the Drosophila paulistorum complex. Evolution 25:129-143.

Spellman PT and Rubin GM (2002) Evidence for large domains of similarly expressed genes in the Drosophila genome. J Biol $1: e 5$

Sperlich D and Pfriem P (1986) Chromosomal polymorphism in natural and experimental populations In: Ashburner M, Carson HL and Thompson Jr JN (eds) The Genetics and Biology 
of Drosophila. Academic Press, London, vol 3e, pp $257-$ 309.

Townsend JI (1952) Genetics of marginal populations of Drosophila willistoni. Evolution 6:428-442.

Valente VLS and Araújo AM (1985) Observations on the chromosomal polymorphism of natural populations of Drosophila willistoni and its association with the choice of feeding and breeding sites. Rev Bras Genet 8:271-284.

Valente VLS and Araújo AM (1986) Chromosomal polymorphism, climatic factors, and variation in population size of Drosophila willistoni in Southern Brazil. Heredity 57:149-159.

Valente VLS and Morales NB (1985) New inversions and qualitative description of inversion heterozygotes in natural populations of Drosophila willistoni inhabiting two different regions in the State of Rio Grande do Sul, Brazil. Rev Bras Genet 8:167-173.

Valente VLS, Ruszczyk A and Santos RA (1993) Chromosomal polymorphism in urban Drosophila willistoni. Rev Bras Genet 16:307-317.

Valente VLS, Rohde C, Valiati VH, Morales NB and Goñi B (2001) Chromosome inversions occurring in Uruguayan populations of Drosophila willistoni. Drosophila Inform Serv 84:55-59.

Valente VLS, Goñi B, Valiati VH, Rohde C and Morales NB (2003) Chromosomal polymorphism in Drosophila willistoni populations from Uruguay. Genet Mol Biol 26:163-173.

Vicario S, Moriyama EN and Powell JR (2007) Codon usage in twelve species of Drosophila. BMC Evol Biol7:e226.
Wallace B (1953a) Coadaptation and the gene arrangements of Drosophila pseudoobscura. In: International Union of Biological Sciences Symposium on Genetics of Population Structure. Fusi, Pavia, pp 67-94

Wallace B (1953b) On coadaptation in Drosophila. Am Nat 87:343-358.

Wu CI and Beckenbach AT (1983) Evidence for extensive genetic differentiation between the sex ratio and the standard arrangement of Drosophila pseudoobscura and D. persimilis and identification of hybrid sterility factors. Genetics 105:71-86.

\section{Internet Resources}

Hammer Ø, Harper DAT and Ryan PD (2001) PAST: Paleontological Statistics software package for education and data analysis. Palaeontologia Electronica 4:1-9. http://folk.uio.no/ohammer/past (December 1, 2010).

\section{Supplementary Material}

The following online material is available for this article:

- Figure S1 - Reference photomap of Drosophila willistoni.

This material is available as part of the online article from http://www.scielo.br/gmb.

License information: This is an open-access article distributed under the terms of the Creative Commons Attribution License, which permits unrestricted use, distribution, and reproduction in any medium, provided the original work is properly cited. 

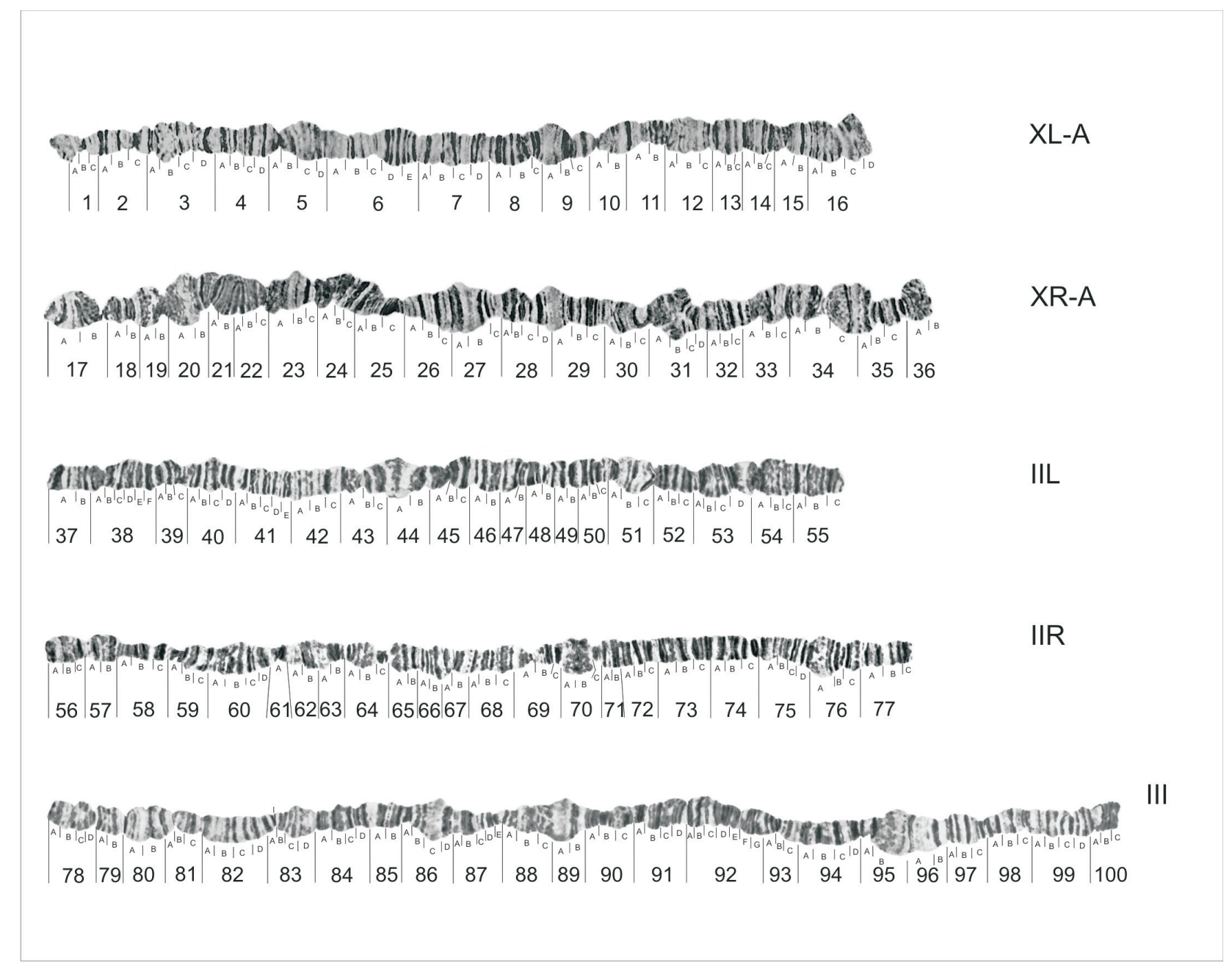

$X L-A$

Figure S1 - Reference photomap of Drosophila willistoni. 